\title{
Statistical Optimization of Co-stabilized Growth of Ag NPs by Liquid Plasma Interaction Method for Study of Antibacterial Activity
}

Noorul Huda ( $\nabla$ noorulhuda100@yahoo.com )

University of Agriculture Faisalabad

M. Y. Naz

Department of Physics, University of Agriculture, 38040 Faisalabad, Pakistan

M. Ayyaz

Department of Physics, University of Agriculture, 38040 Faisalabad, Pakistan

S. Shukrullah

Department of Physics, University of Agriculture, 38040 Faisalabad, Pakistan

\section{Research Article}

Keywords: Silver NPs, plasma electrolysis, mono and poly-saccharides, response surface methodology, antibacterial activity

Posted Date: June 30th, 2021

DOl: https://doi.org/10.21203/rs.3.rs-660951/v1

License: (9) This work is licensed under a Creative Commons Attribution 4.0 International License. Read Full License 


\section{Abstract}

In this study, a plasma jet of argon gas was impinged with a solution of metal salt and stabilizers for production of silver NPs. To optimize the absorbance parameter, a simplex centroid design (SCD) was used to optimize the experiments. The combined and individual effect of stabilizers on the synthesis of Ag NPs was significant when P-value $<0.05$. SCD optimization of UV results showed a sharp SPR band at $302 \mathrm{~nm}$. In FTIR analysis, bond absorption at $1633 \mathrm{~cm}-1$ attributed to $\mathrm{C}=0$ was shifted to higher wavelength due to saccharides addition. XRD analysis confirmed the FCC structure of Ag NPs having average size of $15 \mathrm{~nm}$. SEM- EDX revealed the formation of spherical shaped Ag NPs with strong absorption at $3 \mathrm{keV}$ confirming the presence of the Ag content. Antibacterial activity of Ag NPs was significant against both bacteria, with slightly stronger activity against Staph. aureus than Escherichia coli.

\section{Full Text}

This preprint is available for download as a PDF. 